\title{
Age differences in the association between stressful work and sickness absence among full-time employed workers: evidence from the German socio-economic panel
}

\author{
Simon Götz ${ }^{1}$ (1) $\cdot$ Hanno Hoven ${ }^{1} \cdot$ Andreas Müller $^{2} \cdot$ Nico Dragano $^{1} \cdot$ Morten Wahrendorf $^{1}$
}

Received: 31 May 2017 / Accepted: 20 February 2018 / Published online: 28 February 2018

(c) The Author(s) 2018. This article is an open access publication

\begin{abstract}
Purpose We aim to extend current knowledge on associations between stressful work and sickness absence, first, by studying associations between ERI and sickness absence among full-time employees from various occupations, and second, by investigating if associations vary by age.

Methods We use data from four waves of the German socio-economic panel (GSOEP), collected among men and women between 2006 and 2012, with 9418 observations. Stressful work is measured with a short form of the ERI questionnaire. We investigate an imbalance between effort and reward (ER ratio) as well as the two main components ("high effort" and "low reward"). Sickness absence is measured by self-reported number of sickness days (assessed the following year). After descriptive analyses, we estimate a series of multivariable regressions, including tests for interactions between age and work stress. Results Each of the three indicators of stressful work is related to higher number of sickness days, with except of "high effort" in case of men. Findings remain significant after adjusting for social position (income, education and occupational class) and health. In addition, for both men and women, associations were slightly higher among older workers, though interactions did not reach statistical significance.

Conclusion Our findings support that stressful work is linked to sickness absence across a wide spectrum of jobs with varying incomes and educational levels, and also that associations are slightly more pronounced among older workers.
\end{abstract}

Keywords Work stress $\cdot$ Effort-reward imbalance $\cdot$ Sickness absence $\cdot$ Age differences $\cdot$ GSOEP

\section{Introduction}

Sickness-related absence from work is a major concern of today's labour markets and ageing workforces in Europe. For example, according to Eurofound, the average rate of sickness absence in the European Union varies between

Electronic supplementary material The online version of this article (https://doi.org/10.1007/s00420-018-1298-3) contains supplementary material, which is available to authorized users.

Simon Götz

simon.goetz@hhu.de

1 Institute of Medical Sociology, Centre for Health and Society, Medical Faculty, University of Duesseldorf, Universitaetsstrasse 1, 40225 Duesseldorf, Germany

2 Institute of Psychology, Work and Organizational Psychology, University of Duisburg-Essen, Universitätsstrasse 2, 45141 Essen, Germany
3 and 6\% (Eurofound 2010). This has considerable consequences for companies and national health policies, as it decreases productivity and increases costs for health insurances. Studying predictors of sickness absence, therefore, is important, as it helps to identify factors related to sickness absence and to develop workplace health interventions.

Studies from several countries have identified different factors that are related to sickness-related absence from work (Beemsterboer et al. 2009; Harrison and Martocchio 1998), including sociodemographic factors and psychosocial working conditions. When it comes to sociodemographic factors, for example, findings show that older workers have generally more days of sickness absence than younger workers (Donders et al. 2012; Taimela et al. 2007). Studies also highlight that patterns and reasons for sickness absence differ between women and men, with levels being generally higher among women-a finding that may be related to differing significance of the work role (Casini 
et al. 2013; Krantz and Lundberg 2006; Messing et al. 2003; Siegrist et al. 2006; Sterud 2014). Stressful working conditions are another factor related to sickness absence, mainly because of their health-related consequences. This was shown by various occupational cohort studies. Thereby, measures of stressful work range from established theoretical models, such as job strain (Ala-Mursula et al. 2005; Mortensen et al. 2017), effort-reward imbalance (Ala-Mursula et al. 2005; Derycke et al. 2013; du Prel et al. 2015; Fahlén et al. 2009; Lidwall 2016; Schreuder et al. 2010) or relational injustice (Head et al. 2007), to single stressors at work (Brussig and Ahlers 2007). Yet, despite this consistent evidence linking work stress to sickness absence, studies are generally based on rather homogenous occupational cohorts, such as nurses (Farquharson et al. 2012; Schreuder et al. 2010), transport operators (Cunradi et al. 2005), teachers (Derycke et al. 2013), university employees (Donders et al. 2012) or civil servants (Head et al. 2007). Similarly, most cohorts are recruited during midlife, and thus, older workers are clearly underrepresented in existing studies. This focus on midlife and on homogenous occupational groups, however, has at least two consequences for scientific knowledge about the association between stressful work and sickness absence.

First, more studies are needed that establish the links between work stress and sickness absence across various occupational groups that cover a wide spectrum of jobs with varying incomes and educational levels. This would help to rule out that associations between stressful work and sickness absence are due to cohort specific characteristics. For example, options and regulations for sickness absence may differ between various occupations, and thus, the links between work stress and sickness absence may vary as well. Therefore, the first aim of the present study is to investigate links between stressful work and sickness absence among the full-time employees from various occupations based on a general population survey.

Second, because of demographic changes and ageing workforces in Europe, it is necessary to extend studies to older workers. This, notably, not just concerns the general question if the overall level of sickness absence differs by age, but also the more specific question if the association between stressful work and sickness absence varies by age. In fact, there is evidence that the impact of stressful work differs depending on the period, or life stage, at which it occurs (Burr et al. 2017; Donders et al. 2012; Payne and Doyal 2010; Sampaio and Augusto 2012; Shultz 2010). Notably, this is in line with an important principle of life course research, which is to consider the timing of an exposure to understand its health-related consequences in more details (Ben-Shlomo and Kuh 2002; Wahrendorf and Chandola 2016). Older persons, for example, may be more vulnerable to work stress, because the ageing process is accompanied by changing coping capabilities and resources (Hobfoll 1989; Lazarus and DeLongis 1983), as well as changes of the physiological system. Older people, therefore, may be more likely to turn sick in case of stressful work, as well as they may take longer to recover. In that case, the association between stress and sickness absence would be more pronounced for older workers. A stronger association for older workers though could also have indirect reasons, because younger workers have possibly different motivations to work than older workers. For example, younger workers may face higher pressure to develop strong ties to the labour market, and therefore, they are more likely to continue working compared to their older counterparts, even if conditions at work are poor. There are, however, also reasons why associations between stress at work and sickness absence could be less pronounced for older workers than for younger workers. For example, older workers may face more difficulties to find a new job in case of job loss, and therefore, they are probably more likely to tolerate adverse conditions than younger workers.

Overall, there are numerous, and partly divergent assumptions on how associations between work stress and sickness absence may differ by age, but evidence on this is lacking. The second aim of this study, thus, is to compare links between work stress and sickness absence between different age groups. In sum, this leads to the following research questions:

(1) Is stressful work associated to sickness-related absence from work for men and women?

(2) If so, does the association between stressful work and sickness-related absence from work differ by age for men and women?

\section{Methods}

\section{Data}

We base our study on the German socio-economic panel (GSOEP) (Schupp et al. 2016). GSOEP is the largest panel study in Germany, based on a random sample of private households. It started 1984 in western Germany with 12,245 respondents from 5921 households with on-going waves of data collection ever since. Data is collected for each household member aged 18 or older, using paper and pencil interviews (PAPI), computer assisted personal interviews (CAPI) and self-completion questionnaires. The response rate in wave 1 was $62 \%$, and the attrition rate between wave 1 and wave 2 was 14\% (for more information 
see: Kroh et al. 2017). In 1990, eastern Germany joined the study. Furthermore, additional subsamples were added in the course of the study to maintain the population representation and to increase the sample size (especially in 2000). At present, GSOEP provides representative data for more than 20,000 adult men and women in Germany taken from nearly 11,000 households. Besides sociodemographic characteristics, this includes information on individual living conditions, work and employment, income, health and sickness-related absence from work. (For more information on the GSOEP data see: Wagner et al. 2007). One of the main advantages of the GSOEP is the longitudinal nature of the information, where information on work stress (available in 2006 and 2011) can be linked to number of sickness days, as collected the year after (2007 and 2012, respectively). For the present study, we focused on men and women aged $18-65$ years in the year of work stress assessment $(33,648$ observations) and applied the following sample restrictions: First, we excluded those who were not working and had no information on sickness absence for the year after $(12,994$ observations). Second, we excluded those who were working in part-time (5719 observations), because part-time workers often not work five days the week, making comparisons of days in sickness absence with full-time workers impossible. Third, we excluded people who either were in vocational training or in military service ( 850 observations), because employment relations and salary regulations are different for these groups. Fourth, people who changed their job during the observation period were also excluded (981 observations), because the association between work stress and sickness absence days is unclear. Fifth, we excluded people who were self-employed (1677 observations), as self-employed workers are not automatically qualified for statutory sick pay in case of sickness. Sixth, we decided to exclude people who were permanently sick (with more than 200 days of sickness absence, 57 observations), since they hardly participated on the labour market. Finally, among these remaining 11,370 observations, we restricted the sample to those with complete information on all variables under study (excluding another 1952 observations), with no indication of systematic missings. In sum, this results in a final sample of 9418 observations (person-year observations) with complete data on all study variables (based on 7193 individuals, each observed on average in 1.3 observation periods).

\section{Measures}

\section{Work stress}

Work stress is measured by the short version of the ERI questionnaire, as validated by a previous study for the GSOEP (Siegrist et al. 2009). The ERI model identifies stressful work in terms of an imbalance between high efforts spent at work and low rewards received in turn (Siegrist and Wahrendorf 2016). The short version of the questionnaire includes three items for effort and seven items for reward. Items for effort refer to perceived psychological demands at work, and reward includes salary, esteem, job security and career opportunities. Each item is listed in Supplementary Table S1. In GSOEP, items are rated on a five-point scale, ranging from 'disagree', via 'agree, and I am somewhat distressed', to 'agree, and I am very distressed'. For the analyses, we followed established procedures and created sum-scores for effort and reward, as well as we calculate the ratio between effort and reward (adjusted for number of items). On this basis, we first create two binary indicators for each of the two main components. Specifically, to identify elevated levels of work stress, people who belonged to the highest tertile of the effort-scale were classified as "high effort" and those in the lowest tertile of the reward scale as "low reward" (in both cases tertiles are based on the total sample in work). Then, effort-reward imbalance was calculated by dividing the sum score of the 'effort' items (nominator) through the sum score of the 'reward' items (adjusted for number of items; denominator). This results in a sum score where higher values are related to higher levels of work stress. For the analyses, an imbalance was assumed in case values are higher than 1 (labelled as "ER ratio $>1$ "). In sum, this leads to three different binary indicators of stressful work. More details on psychometric properties for GSOEP (Siegrist et al. 2009) and on the conceptual basis are fully described elsewhere (Siegrist 2016).

\section{Sickness days}

To measure sickness-related absence from work, the present study relies on the total number of days of absence from work. More specifically, in the year following the assessment of work stress respondents answered an open question on how many days they were not able to work because of illness in the previous year. In contrast to other approaches focusing on number of absence episodes, this reflects the total absence duration in 1 year (possibly based on several episodes) (Steel 2003).

\section{Age groups}

We distinguish four age groups for the analyses, each covering a distinct phase in the life course (Willis and Martin 2005). The first group, "Job starters" (Age 18 till a 29), covers the period where people make first experiences on the labour market. Next, "early midlife" (age 30-45) 
and "late midlife" (age 46-57) refer to the main phase of working life, accompanied by increasing responsibilities at work and parenthood, and progressing ageing processes. Lastly, "older working life" (58-65 years) represents those who approach the end of working life.

\section{Additional measures}

We also include two sociodemographic measures (partnership and number of young children), three indicators of the respondent's social position (education, income and occupational position), and self-rated health. In the case of partnership, we use a binary indicator of whether the respondents live with a partner (regardless of the marital status). The number of young children (aged 14 or younger) is regrouped into "none", " 1 " and " 2 or more". As an indicator of education, we use the total years spent in full-time education. Income is based on the monthly household income that we adjusted for household size in accordance with the
OECD equivalent-scale (Burniaux et al. 1998), and thereafter regrouped into income tertiles ("high", "medium" and "low"). Occupational position is measured according to the Erikson-Goldthorpe-Portocarero scheme (EGP scheme) (Erikson and Goldthorpe 1992). This scheme classifies occupations into seven classes based on specific aspects under which a person performs work on the labour market, or more specifically, "employment relations". For the analyses, occupations were regrouped into four categories: "upper service class" (EGP I), "lower service class" (EGP II), "routine non-manuals workers" (EGP III, IVab), and "skilled and unskilled manual workers" (EGP IVc, V, VI, VII). Self-rated health was measured by a single question ("How would you describe your current health?") with five categories ranging from "very good" to "bad". Answers were dichotomized into "good or better" and "less than good". An overview of all measures is presented in Table 1.
Table 1 Sample description: observations (No.) and percentage $(\%)$ or mean and standard deviation $(\mathrm{SD})$ : $n=9418$

\begin{tabular}{|c|c|c|c|}
\hline & Range or categories & No. or (mean) & $\%$ or $(\mathrm{SD})$ \\
\hline \multirow[t]{2}{*}{ Sex } & Male & 6257 & 66.4 \\
\hline & Female & 3161 & 33.6 \\
\hline \multirow[t]{4}{*}{ Age groups } & Job starters (18-29) & 1036 & 11.0 \\
\hline & Early midlife (30-45) & 3894 & 41.3 \\
\hline & Late midlife (46-57) & 3511 & 37.3 \\
\hline & Older working life (58-65) & 977 & 10.4 \\
\hline Sickness days & Range: $0-200$ days & $(9.1)$ & $(20.0)$ \\
\hline \multirow[t]{2}{*}{ High effort } & Yes & 2714 & 28.8 \\
\hline & No & 6704 & 71.2 \\
\hline \multirow[t]{2}{*}{ Low reward } & Yes & 3639 & 38.6 \\
\hline & No & 5779 & 61.4 \\
\hline \multirow[t]{2}{*}{ ER ratio $>1$} & Yes & 1391 & 14.8 \\
\hline & No & 8027 & 85.2 \\
\hline \multirow[t]{4}{*}{ Occupational position } & Higher service class & 1739 & 18.5 \\
\hline & Lower service class & 2721 & 28.9 \\
\hline & Routine non-manuals & 1682 & 17.9 \\
\hline & Skilled and unskilled manual workers & 3276 & 34.8 \\
\hline Years in job & Range: $0-50$ years & $(13.6)$ & $(10.5)$ \\
\hline \multirow[t]{3}{*}{ Income } & High & 4606 & 48.9 \\
\hline & Medium & 3369 & 35.8 \\
\hline & Low & 1443 & 15.3 \\
\hline Education years & Range: $7-18$ years & $(12.9)$ & $(2.8)$ \\
\hline \multirow[t]{3}{*}{ Number of children $<14$} & None & 6923 & 73.5 \\
\hline & 1 & 1347 & 14.3 \\
\hline & 2 or more & 1148 & 12.2 \\
\hline \multirow[t]{2}{*}{ Partnership } & Living with partner & 7937 & 84.3 \\
\hline & Living as single & 1481 & 15.7 \\
\hline \multirow[t]{2}{*}{ Self-rated health } & Good or better & 5457 & 57.9 \\
\hline & Less than good & 3961 & 42.1 \\
\hline Total & & 9418 & 100.0 \\
\hline
\end{tabular}


Table 2 High levels of stress at work (in percent) and sickness days [mean values, standard deviation, median and interquartile range (IQR)] by covariates: $n=9418$

\begin{tabular}{|c|c|c|c|c|c|c|c|}
\hline & High efforts & Low reward & ER ratio $>1$ & Sickn & lays & & \\
\hline & $\%$ & $\%$ & $\%$ & Mean & & Median & IQR \\
\hline Sex & & & & & & & \\
\hline Male & 28.1 & 37.0 & 13.8 & 8.6 & $(19.6)$ & 2 & 10 \\
\hline Female & 30.3 & 41.8 & 16.7 & 10.3 & $(20.8)$ & 4 & 10 \\
\hline Age groups & & & & & & & \\
\hline Job starters (18-29) & 22.4 & 30.2 & 9.7 & 7.3 & $(15.3)$ & 4 & 8 \\
\hline Early midlife (30-45) & 29.0 & 40.8 & 15.5 & 8.0 & $(18.1)$ & 3 & 10 \\
\hline Late midlife (46-57) & 31.4 & 40.9 & 16.3 & 10.0 & $(21.2)$ & 3 & 10 \\
\hline Older working life (58-65) & 25.4 & 30.8 & 11.5 & 12.5 & $(25.9)$ & 3 & 14 \\
\hline Occupational position & & & & & & & \\
\hline Higher service class & 37.8 & 30.9 & 15.1 & 6.6 & $(15.5)$ & 2 & 6 \\
\hline Lower service class & 30.8 & 37.5 & 15.1 & 8.7 & $(18.6)$ & 3 & 10 \\
\hline Routine non-manuals & 30.1 & 40.6 & 16.0 & 9.0 & $(20.0)$ & 3 & 10 \\
\hline Skilled and unskilled manual workers & 21.7 & 42.6 & 13.7 & 10.9 & $(22.9)$ & 3 & 11 \\
\hline Income & & & & & & & \\
\hline High & 32.8 & 34.0 & 14.0 & 8.4 & $(18.7)$ & 3 & 10 \\
\hline Medium & 26.8 & 42.7 & 15.7 & 9.8 & $(20.8)$ & 3 & 10 \\
\hline Low & 20.9 & 43.9 & 15.1 & 10.0 & $(22.0)$ & 3 & 10 \\
\hline Number of children $<14$ & & & & & & & \\
\hline None & 29.1 & 38.5 & 14.8 & 9.7 & $(21.1)$ & 3 & 10 \\
\hline 1 & 29.0 & 41.4 & 16.2 & 8.9 & (19.1) & 3 & 10 \\
\hline 2 or more & 26.8 & 36.3 & 12.6 & 6.5 & $(12.9)$ & 3 & 8 \\
\hline Partnership & & & & & & & \\
\hline Living with partner & 29.2 & 38.7 & 14.7 & 9.1 & (20.4) & 3 & 10 \\
\hline Living as single & 26.9 & 38.4 & 15.3 & 9.2 & (19.9) & 3 & 10 \\
\hline Self-rated health & & & & & & & \\
\hline Good or better & 23.4 & 31.0 & 9.7 & 5.8 & (13.4) & 2 & 6 \\
\hline Less than good & 36.2 & 49.2 & 21.8 & 13.7 & $(25.8)$ & 5 & 14 \\
\hline Total & 28.8 & 38.6 & 14.8 & 9.1 & (20.0) & 3 & 10 \\
\hline
\end{tabular}

\section{Analytical strategy}

We start with a basic sample description (Table 1). Thereafter, Table 2 explores how the three measures of work stress and number of sickness days are distributed by covariates. We also report tests of significance based on Chi-square, Wilcoxon-Mann-Whitney, or Kruskal-Wallis tests. Then, a first picture of the associations between work stress and sickness absence, and their variations by age, is presented in Table 3. Specifically, we show the mean number and the median of sickness days for each age group separately, including confidence intervals (95\%), interquartile ranges (IQR) and tests of significance (Wilcoxon-Mann-Whitney test). In this case (and in later multivariable regressions), analyses consider sex differences and are conducted for men and women separately (Casini et al. 2013; Messing et al. 2003).
Next, we estimate a series of multivariable regression models using sickness days as dependent variableagain for each age group separately, as well as for all ages (Table 4). Importantly, these models consider the hierarchical structure of our data, that is, that some observations (level 1) are not independent, as they come from the same respondent nested in different survey years (level 2). In these models, the constant is allowed to vary within individuals (also called random intercept model for longitudinal data or "random-effect model" for panel data) (Andreß et al. 2013; Giesselmann and Windzio 2012). Unlike a "fixedeffect model" for panel data, this allows to include time constant predictors (e.g. education, income and occupational position). In addition, models are both presented for nontransformed (for ease of interpretation) and transformed sickness days, because sickness days were not normally distributed. For this, we compared different transformations 


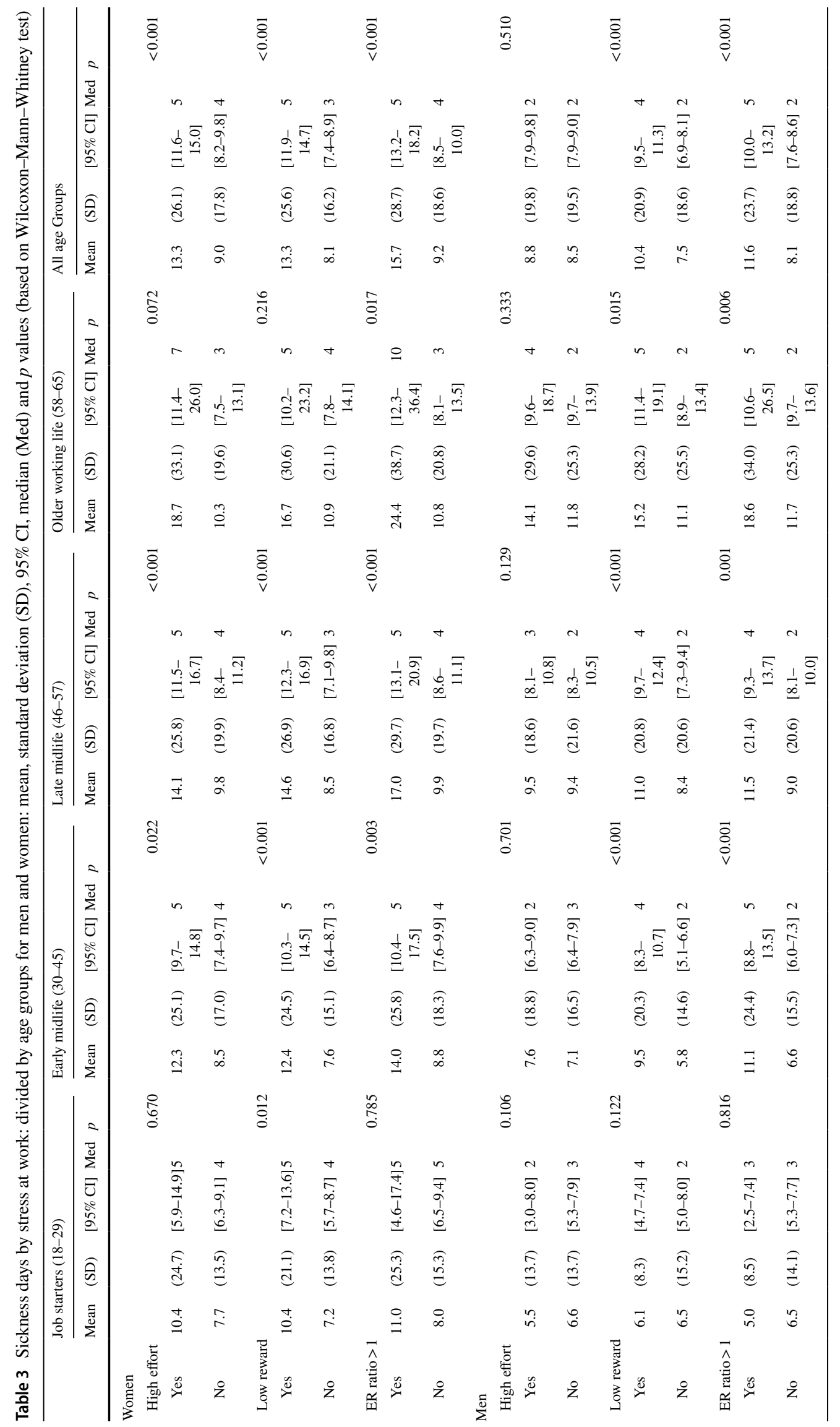




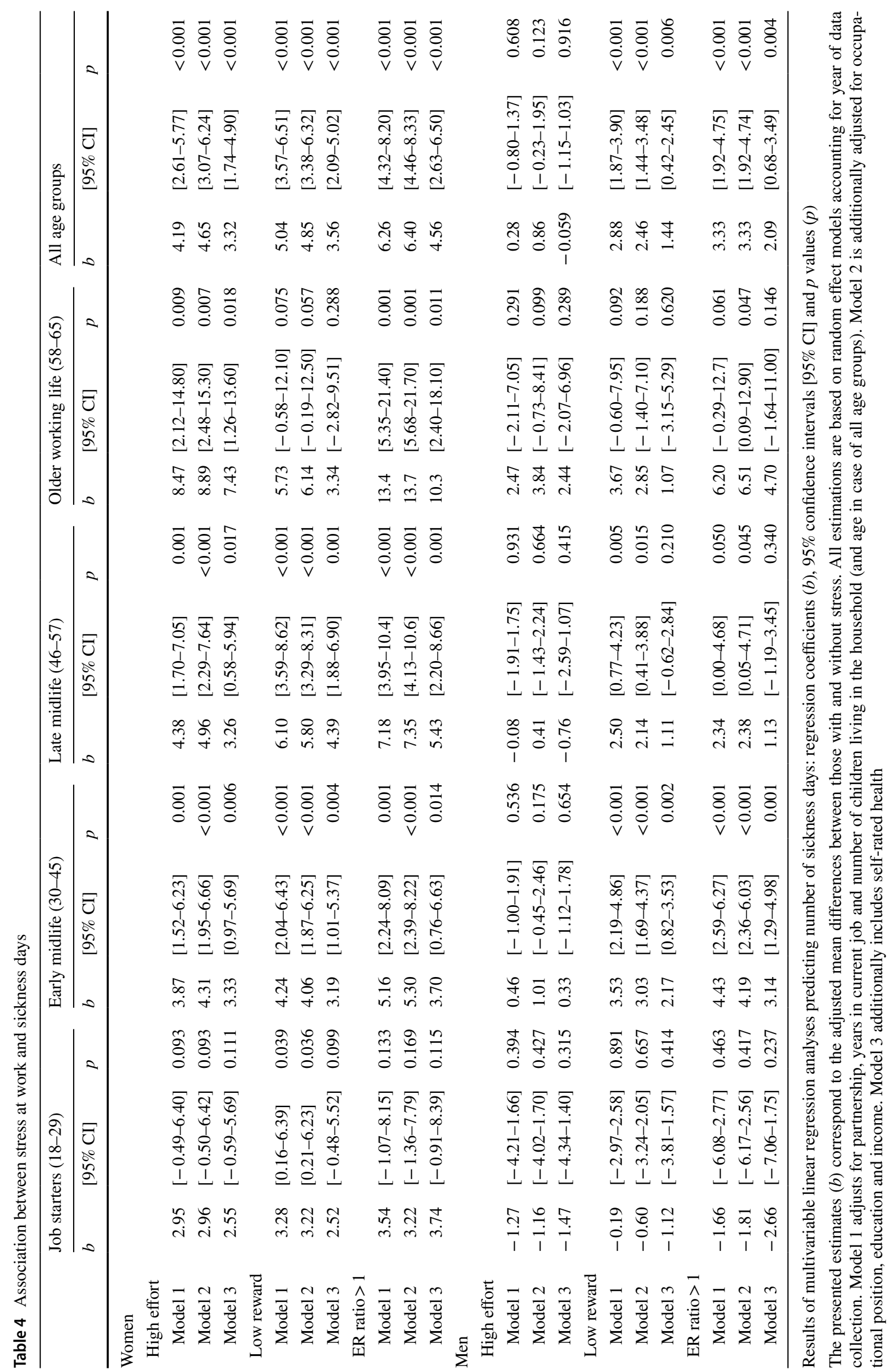


and decided to adopt a square root transformation (Stoto and Emerson 1983). In sum, we present estimates of three regression models, estimated for each measure of work stress separately (maximum likelihood estimation). Model 1 presents estimates that are adjusted for partnership situation, years in job and number of young children. After checking for potential multicollinearity, model 2 adds education, income and occupational position, and thus, looks if associations remain consistent after accounting for social position. Model 3 then includes health to investigate a possible mediation via health (or confounding). Based on these regression models, we can already compare the effect sizes between the age groups. Then, to formally test interactions between work stress and age groups, we use the total sample and include interaction terms between work stress and each age group into the model. We hereby rely on model 2 (adjusting for sociodemographic factors and social position) and do not include health as potential mediator (or intermediate variable on the causal path between work stress and sickness absence) to avoid overadjustment. By comparing models without and with interactions on the basis of a likelihood-ratio test, we test for significant interactions (Mitchell 2012).

At last, to summarize our main findings, we predict days of sickness absence based on multivariable regression models for each age group by levels of work stress (as exemplified by ER ratio $>1$ ), and show predicted values in Fig. 1. All calculations and the graph are produced with Stata 14.

\section{Results}

\section{Descriptive findings}

The sample described in Tables 1 and 2 explores links between work stress and sickness days. Overall, the sample includes more men than women, and most workers belong to the two middle age groups ("early midlife" and "late midlife"). Respondents spent on average about 13 years in full-time education. Most respondents work in the lower service class or as manual worker (skilled or unskilled), live in a partnership, and are in good health. About $15 \%$ of the sample has an ER ratio above 1. The overall mean score of sickness days is 9.1 (with a standard deviation of 20.0). As we see in Table 2, medians of sickness days are generally smaller than the mean values, pointing to a right skewed distribution of sickness days.

\section{Distribution of work stress and sickness days by covariates}

We see that work stress and sickness days vary by covariates under study: Men both have lower levels of work stress and fewer sickness days than women. In case of age, there is a positive association with sickness days, where number of days is higher in older age groups. Work stress, however, has an inverse u-shape association with age, with lower levels of work stress among youngest and oldest worker and higher values in the two middle age-categories (for each indicator of work stress). Turning to income and occupational position, it is worth noting that only low reward follows a social
Fig. 1 Predicted number of sickness days by work stress (ER ratio $>1$ ) and age groups for women and men with $95 \%$ confidence intervals. Predicted scores are adjusted for partnership, years in current job, number of children living in the household, occupational position, education and income (Model 2 in Table 4)

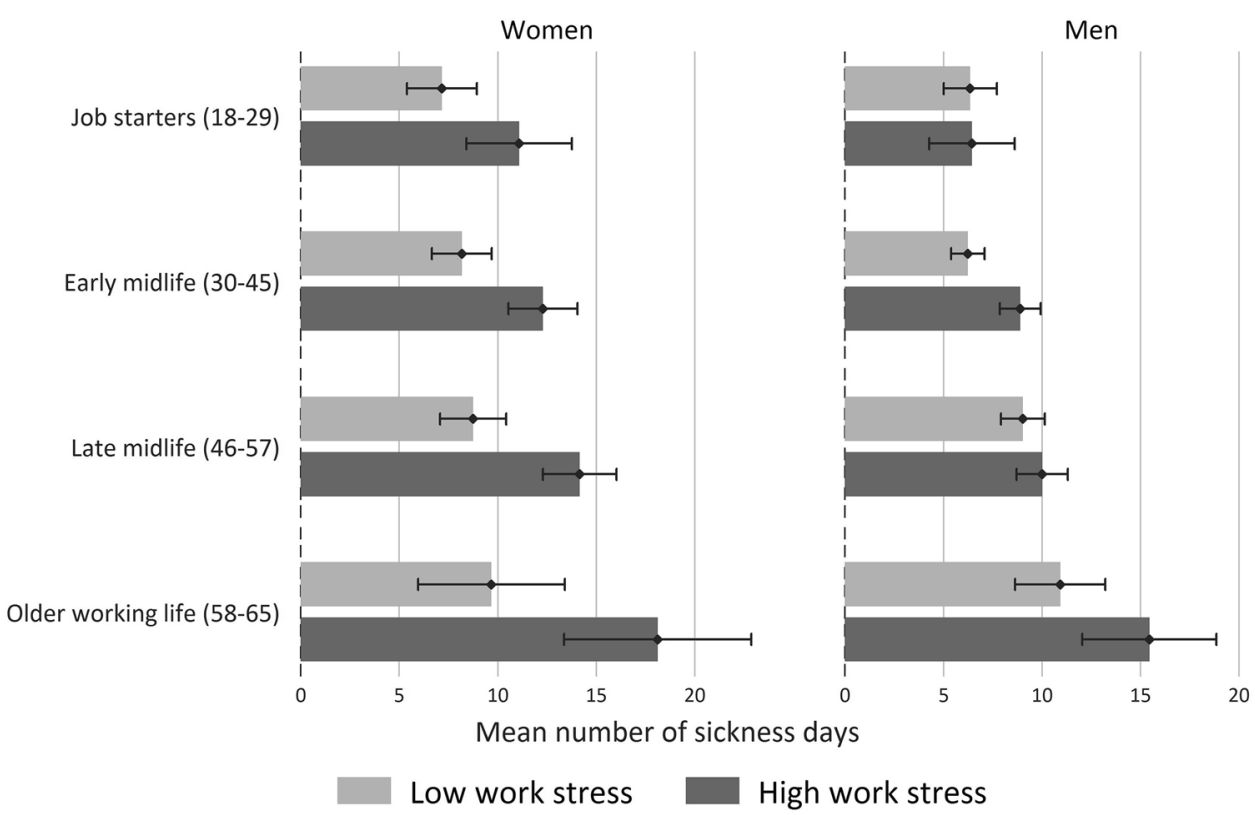


gradient (where working conditions are better for people with an advantaged social position). In case of sickness days, however, a disadvantaged occupational position is related to more sickness days. Finally, we see that days of sickness absence and levels of work stress are higher amongst people with poor health. In all cases, the reported associations are statistically significant, with $p$ values below 0.05 (not reported in Table 2).

\section{Association between work stress and sickness days}

Table 3 shows that sickness days are generally related to levels of work stress, not only in the total sample, but also within each age group. Yet, a closer look reveals three interesting findings: First, differences in sickness days appear somewhat larger for women than for men. Second, for women all indicators of work stress are clearly related to sickness days, while a relation between high effort and sickness days is not apparent for men. Third, it seems that differences are slightly more pronounced among older age groups (for men and women).

Table 4 presents results of the multivariable regressions based on non-transformed sickness days, and the results for transformed sickness days (square root) are presented in Table 5. For each of the indicators of work stress, three models with different adjustment sets were estimated. Since we present unstandardized coefficients (denoted as "b"), the estimates in Table 4 correspond to the adjusted mean differences in sickness days between those with and those without work stress. In sum, findings confirm the results from above and suggest that the reported associations are statistically significant (specifically for all age groups combined). Besides, four points are worth being noted: First, coefficients remain almost unchanged after accounting for social position in Model 2, thus, suggesting that links between work stress and sickness absence are not confounded by social position. Second, albeit coefficients remain statistically significant in most cases after inclusion of self-related health in model 3, estimates are generally attenuated. This suggests that parts of the association between work stress and sickness absence are due to poor health, but also that there is an independent effect. Third, when comparing estimates between the four age groups, they are somewhat higher in the oldest age group. Fourth, findings are consistent for non-transformed and transformed sickness days. Fig. 1 summarizes main findings, where days of sickness absence are predicted based on Model 2 in Table 4.

To formally test interactions between work stress and age groups, Table 6 (for non-transformed sickness days) and Table 7 (transformed sickness days) again investigates if work stress is linked to sickness absence across all ages (former Model 2), and then includes interactions between work stress and age groups (Model 2a). Two observations deserve attention: First, we again see that each measure of work stress is linked to increased number of sickness days, except of high effort in case of men. Second, once we include interactions in model 2 (indicating the difference in effects of work stress to the youngest age group), we observe that interactions are highest for the oldest age group, yet, they do not reach statistical significance. Thus, while effects tend to be higher for older workers, we cannot fully rule out that our findings of higher estimates in older groups are due to random errors. Again, findings are consistent for non-transformed and transformed sickness days.

\section{Discussion}

This study used data from the GSOEP, collected among employed men and women in Germany, and investigated how stress at work (measured in terms of effort-reward imbalance and its two main components) is linked to subsequent number of sickness days (assessed 1 year later). In addition, the study compared associations of stress at work and sickness days between different age groups. According to these two research questions, two major findings result from our analyses: First, we found clear support that stressful work is linked to a higher number of sickness days. Yet, while this was true for each of the studied indicators in case of women (high effort, low reward and ER ratio $>1$ ), we found no association for high effort in case of men. Importantly, associations persisted after accounting for three indicators of social position (education, income and occupational position), and additionally, they remained significant after adjusting for individual health at baseline. The second major finding was that associations were generally stronger amongst older worker, both for men and women. In analyses testing formally for effect modification, though, interactions between age and stress at work did not attained statistical significance.

Overall, our findings are in line with previous studies, specifically studies linking a effort-reward imbalance with sickness absence (Ala-Mursula et al. 2005; Derycke et al. 2013; du Prel et al. 2015; Fahlén et al. 2009; Lidwall 2016; Schreuder et al. 2010), but they also refine and add to existing knowledge in several ways:

First, by investigating associations among German full-time employees from various occupations and analysing sickness days in the year following the assessment of stress at work (1-year follow-up period), we extend existing evidence that was so far restricted to cross-sectional findings (du Prel et al. 2015) or to homogeneous 


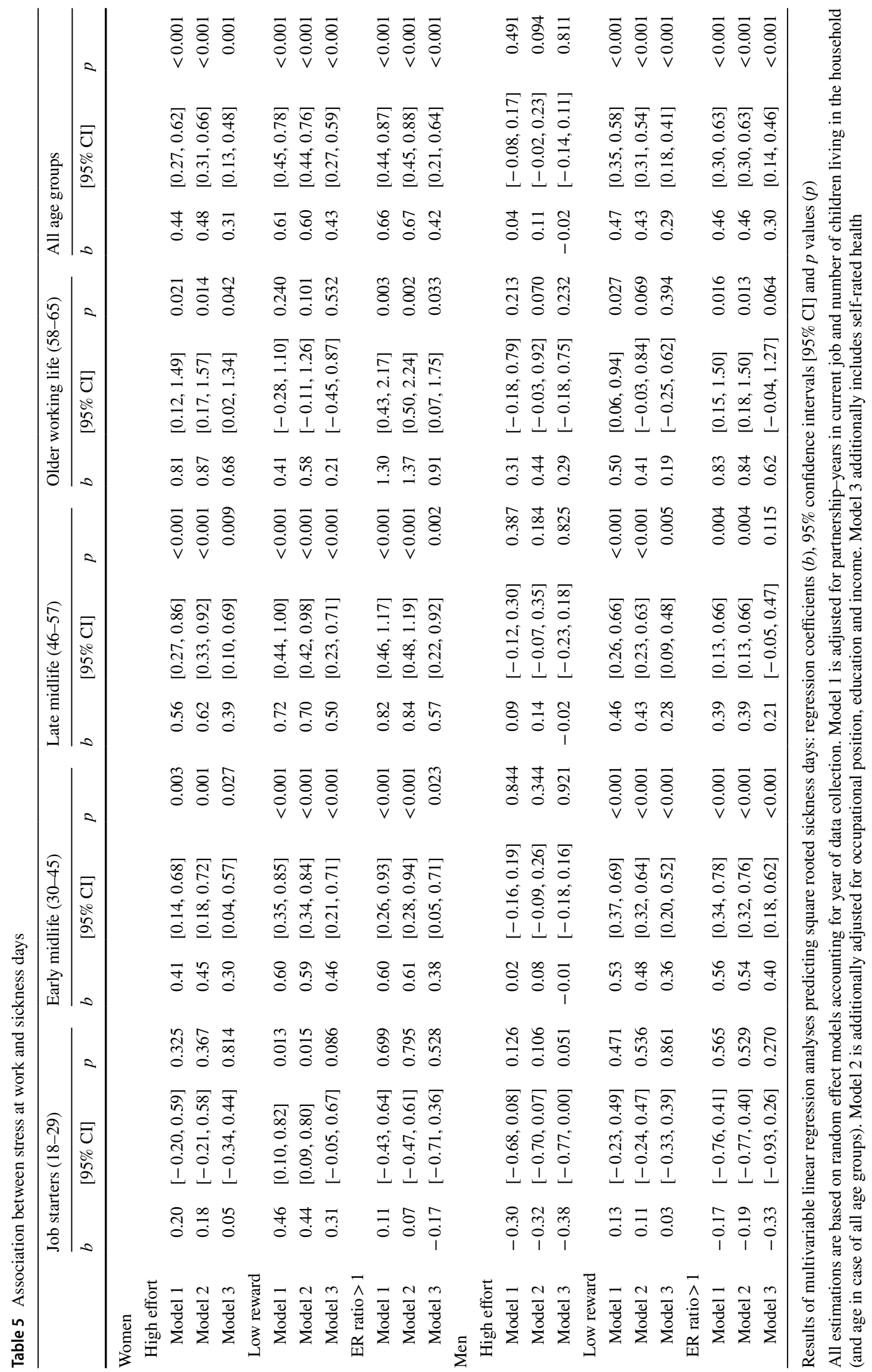


Table 6 Interactions between stress at work and age group on sickness days

\begin{tabular}{|c|c|c|c|c|c|c|c|c|c|}
\hline & \multicolumn{3}{|c|}{ High effort } & \multicolumn{3}{|c|}{ Low reward } & \multicolumn{3}{|c|}{ ER ratio $>1$} \\
\hline & $b$ & {$[95 \% \mathrm{CI}]$} & $p$ & $b$ & {$[95 \% \mathrm{CI}]$} & $p$ & $b$ & {$[95 \% \mathrm{CI}]$} & $p$ \\
\hline \multicolumn{10}{|l|}{ Women } \\
\hline \multicolumn{10}{|l|}{ Model 2 [without interactions] } \\
\hline High stress & 4.65 & {$[3.07-6.24]$} & $<0.001$ & 4.85 & {$[3.38-6.32]$} & $<0.001$ & 6.40 & {$[4.46-8.33]$} & $<0.001$ \\
\hline \multicolumn{10}{|l|}{ Model 2a (with interactions) } \\
\hline High stress (main effect) & 3.14 & {$[-1.12-7.41]$} & 0.149 & 2.98 & {$[-0.84-6.79]$} & 0.126 & 3.12 & {$[-2.48-8.72]$} & 0.275 \\
\hline High stress early midlife [30-45] & 1.05 & {$[-3.89-5.99]$} & 0.677 & 1.57 & {$[-2.89-6.02]$} & 0.491 & 2.00 & {$[-4.37-8.38]$} & 0.538 \\
\hline High stress late midlife [46-57] & 1.60 & {$[-3.35-6.54]$} & 0.526 & 2.71 & {$[-1.77-7.19]$} & 0.235 & 4.10 & {$[-2.27-10.5]$} & 0.207 \\
\hline High stress older working life [58-65] & 5.61 & {$[-1.18-12.40]$} & 0.105 & 2.82 & {$[-3.61-9.26]$} & 0.390 & 10.2 & {$[1.47-19.0]$} & 0.022 \\
\hline $\begin{array}{l}p \text { values of LR-test comparing model } 1 \\
\text { and } 2\end{array}$ & 0.403 & & & 0.658 & & & 0.097 & & \\
\hline \multicolumn{10}{|l|}{ Men } \\
\hline \multicolumn{10}{|l|}{ Model 2 (without interactions) } \\
\hline High stress & 0.86 & {$[-0.23-1.95]$} & 0.123 & 2.46 & {$[1.44-3.48]$} & $<0.001$ & 3.33 & {$[1.92-4.74]$} & $<0.001$ \\
\hline \multicolumn{10}{|l|}{ Model 2a (with interactions) } \\
\hline High stress (main effect) & -1.05 & {$[-5.03-2.94]$} & 0.607 & -0.72 & {$[-4.42-2.99]$} & 0.704 & -1.32 & {$[-7.44-4.81]$} & 0.673 \\
\hline High stress early midlife (30-45) & 2.02 & {$[-2.28-6.32]$} & 0.357 & 3.75 & {$[-0.25-7.75]$} & 0.066 & 5.51 & {$[-0.95-12.0]$} & 0.094 \\
\hline High stress late midlife (46-57) & 1.52 & {$[-2.81-5.86]$} & 0.491 & 2.71 & {$[-1.34-6.76]$} & 0.189 & 3.42 & {$[-3.09-9.92]$} & 0.304 \\
\hline High stress older working life (58-65) & 4.29 & {$[-0.94-9.53]$} & 0.108 & 4.75 & {$[-0.10-9.60]$} & 0.055 & 8.74 & {$[0.97-16.50]$} & 0.028 \\
\hline $\begin{array}{l}p \text { values of LR-test comparing model } 1 \\
\text { and } 2\end{array}$ & 0.391 & & & 0.196 & & & 0.074 & & \\
\hline
\end{tabular}

Results of multivariable linear regression analyses regression coefficients $(b), 95 \%$ confidence intervals [95\% CI] and $p$ values $(p)$

Model 2 corresponds to Model 2 in Table 4 (all age groups). All estimations are based on random effect models accounting for year of data collection, and are adjusted for partnership, years in current job, number of children living in the household, occupational position, education and income

occupational cohorts (Cunradi et al. 2005; Derycke et al. 2013; Donders et al. 2012; Farquharson et al. 2012; Head et al. 2007; Schreuder et al. 2010). Our results suggest that the associations between effort-reward imbalance and sickness days exist across a wide spectrum of jobs with varying incomes and educational levels. A next step would be to explore if the associations (albeit existing across different jobs) vary by occupational groups. To our knowledge, however, no such study exists so far [but only studies that investigate if social position moderates the association between work stress and health (Kuper et al. 2002; Rugulies et al. 2012)].

Second, we found that associations between work stress and sickness absence are slightly higher among older workers. This again extends existing knowledge, which at this point - to the best of our knowledge-is restricted to one cross-sectional study (Donders et al. 2012). However, in this study, the measure of work stress was not based on an explicit theoretical model and the sample was rather selective (employees of a Dutch university). The finding of a slightly stronger relationship for older people may have different reasons. Yet, it is premature to draw far-reaching conclusions about age per se. Rather, our study underlines that age is more than a chronological ageing process. In fact, it is a highly individualized process that incorporates changes of the physiological system and of socioemotional motivations (Carstensen et al. 1999), and resources (Hobfoll 1989), both with relevance for stress processing among older workers and the extent to which a person may feel a desire of being in control at work (Matschinger et al. 1986). Furthermore, the older people are, the more important it is to study stress processing in the light of previous live courses (Lazarus and DeLongis 1983). Specifically, coping skills may be less developed for people who have spent most of their life course in disadvantaged social and economic circumstances. For these people, chronic stress exposure could lead over time to deficient cognitive, emotional and social developments of core capabilities and coping skills (McEwen 2012), leaving them with higher vulnerability to chronic stress at work. Along these lines, future studies may not only study age differences of the associations between work stress and sickness days, but additionally consider factors 
Table 7 Interactions between stress at work and age group on sickness days

\begin{tabular}{|c|c|c|c|c|c|c|c|c|c|}
\hline & \multicolumn{3}{|c|}{ High effort } & \multicolumn{3}{|c|}{ Low reward } & \multicolumn{3}{|c|}{ ER ratio $>1$} \\
\hline & $b$ & {$[95 \% \mathrm{CI}]$} & $p$ & $b$ & {$[95 \% \mathrm{CI}]$} & $p$ & $b$ & {$[95 \% \mathrm{CI}]$} & $p$ \\
\hline \multicolumn{10}{|l|}{ Women } \\
\hline \multicolumn{10}{|l|}{ Model 2 (without interactions) } \\
\hline High stress & 0.48 & {$[0.31,0.66]$} & $<0.001$ & 0.60 & {$[0.44,0.76]$} & $<0.001$ & 0.67 & {$[0.45,0.88]$} & $<0.001$ \\
\hline \multicolumn{10}{|l|}{ Model 2a (with interactions) } \\
\hline High stress (main effect) & 0.22 & {$[-0.26,0.69]$} & 0.371 & 0.43 & {$[0.01,0.85]$} & 0.045 & 0.09 & {$[-0.53,0.71]$} & 0.781 \\
\hline High stress early midlife (30-45) & 0.21 & {$[-0.34,0.75]$} & 0.456 & 0.16 & {$[-0.33,0.65]$} & 0.528 & 0.48 & {$[-0.22,1.19]$} & 0.180 \\
\hline High stress late midlife (46-57) & 0.34 & {$[-0.20,0.89]$} & 0.220 & 0.26 & {$[-0.24,0.75]$} & 0.311 & 0.72 & {$[0.01,1.43]$} & 0.046 \\
\hline High stress older working life [58-65] & 0.62 & {$[-0.13,1.37]$} & 0.108 & 0.092 & {$[-0.62,0.80]$} & 0.801 & 1.18 & {$[0.21,2.15]$} & 0.017 \\
\hline $\begin{array}{l}p \text { values of LR-test comparing model } 1 \\
\text { and } 2\end{array}$ & 0.387 & & & 0.770 & & & 0.081 & & \\
\hline \multicolumn{10}{|l|}{ Men } \\
\hline \multicolumn{10}{|l|}{ Model 2 (without interactions) } \\
\hline High stress & 0.11 & {$[-0.018,0.23]$} & 0.094 & 0.43 & {$[0.31,0.54]$} & $<0.001$ & 0.46 & {$[0.30,0.63]$} & $<0.001$ \\
\hline \multicolumn{10}{|l|}{ Model 2a (with interactions) } \\
\hline High stress (main effect) & -0.32 & {$[0.77,0.14]$} & 0.175 & 0.10 & {$[-0.32,0.53]$} & 0.631 & 0.16 & {$[0.86,0.55]$} & 0.662 \\
\hline High stress early midlife (30-45) & 0.38 & {$[-0.11,0.88]$} & 0.126 & 0.37 & {$[-0.09,0.82]$} & 0.115 & 0.69 & {$[-0.05,1.43]$} & 0.069 \\
\hline High stress late midlife (46-57) & 0.47 & {$[-0.03,0.97]$} & 0.064 & 0.30 & {$[-0.17,0.76]$} & 0.209 & 0.51 & {$[-0.23,1.26]$} & 0.178 \\
\hline High stress older working life (58-65) & 0.72 & {$[0.12,1.32]$} & 0.019 & 0.45 & {$[-0.10,1.01]$} & 0.110 & 1.15 & {$[0.26,2.05]$} & 0.011 \\
\hline $\begin{array}{l}p \text { values of LR-test comparing model } 1 \\
\text { and } 2\end{array}$ & 0.119 & & & 0.377 & & & 0.052 & & \\
\hline
\end{tabular}

Results of multivariable linear regression analyses predicting square rooted sickness days: regression coefficients (b), $95 \%$ confidence intervals $[95 \% \mathrm{CI}]$ and $p$ values $(p)$

Model 2 corresponds to Model 2 in Table 5 (all age groups). All estimations are based on random effect models accounting for year of data collection, and are adjusted for partnership, years in current job, number of children living in the household, occupational position, education and income

from previous stages of the life course (Ben-Shlomo and Kuh 2002; Elder and Johnson 2002) as well as individual coping strategies and resources (Endler and Parker 1990; Scheibe and Zacher 2013).

Furthermore, because we found that high effort was not related to sickness absence for men (but for women), our study points to interesting sex differences. Perhaps, men who report a high level of effort feel very committed to their work [with a high "motivation to attend" (Steers and Rhodes 1978)], and therefore, they are less likely to be absent from work. Or, on a more conceptual level, this finding underlines that theoretical models of work stress should not focus on the level of psychological demands only, at least for men. Another reason, however, could simply be different response styles between men and women (i.e. social desirability) that trigger men to report a higher level of efforts at work than they actually have. Or, another explanation of why high effort does not lead to sickness absence in case of men, could be that men are more likely to recover from high efforts than women, because of traditional gender roles in the division of paid and unpaid work, leaving women with higher responsibilities beyond work
(Casini et al. 2013; Laaksonen et al. 2008). At this point, an interesting question for future studies would again be if associations between work stress and sickness absence vary by occupational position, since coping skills, motivation and resources are probably more developed in advantaged positions.

Finally, because the association between work stress and sickness absence remained significant after accounting for individual health, our study raises the question what other pathways may underlay the observed association (besides health). Researchers, for example, have suggested that it is not only the low "ability to attend" that explains why stressful work leads to higher sickness days, but also that the "motivation to attend" matters as well (Steers and Rhodes 1978). In that case, for example, a stressful workplace may lead to a low motivation among employers, who in turn decide to avoid the stressful working environment (regardless of their health status).

Despite several strengths of our study (large study sample, theory-based assessment of stress at work, 1-year follow up), we have to consider several limitations. First, the measurement of work stress was restricted to one 
time point only. Because every person may be exposed to stress at some point in his or her life course, this not only includes people who are chronically stressed at work, but also people who are only occasionally stressed. As such, more comprehensive measures of work stress would be desirable, for example, repeated exposures or a measure that consider exposure duration as well. Second, our study was restricted to people who were full-time employed, and thus, we excluded an important fraction of todays' labour market in Germany, that is, part-time employees, as well as employers and self-employed people. However, because self-employed people are not automatically eligible for statutory sick pay in Germany, they may represent a specific group of workers who deserve attention in another study. Third, some may argue that self-reported data on sickness absence (as used in our study) are prone to recall bias and less reliable than administrative records. Studies comparing both types of data, though, generally found high levels of agreement between both sources (Ferrie et al. 2005; Voss et al. 2008), as well as we maintain that self-reported data have many advantages compared with register data (e.g. they also include sickness absence that is not "officially" recorded). Fourth, we also must consider that sickness days were not normally distributed. Therefore, our multivariable analyses were additionally performed for transformed sickness days (square root) and we included nonparametric tests when studying bivariate associations. Also, three types of sensitivity analyses were additionally conducted (not shown): We replicated our main findings using both log-transformation of sickness days and negative binomial regressions. Furthermore, we performed all analyses with an alternative binary outcome measuring long-term sickness absence (30 days or more). Again, results were similar to the one reported and further supported our findings. As fifth limitation, we must consider that our analysis is based on data from Germany collected in 2006 and 2011, thus, we need to ask if results apply to today's workforce or to other countries with different regulations for sickness benefits. Yet, at least for Germany, national regulations have not changed since 2006, including period with continued salary and benefit generosity. Sixth, the study did not consider the reason for sickness absence, for example, whether it was due to musculoskeletal disorders, accident, or to mental health problems. Indeed, we could ask if findings differ by reasons of sickness absence. Yet, GSOEP does not collect information on sickness absence reasons, and to investigate these questions in more detail, we clearly need larger sample sizes allowing meaningful analyses of subgroups. Finally, since the analyses excluded people who were not working at baseline, we may have excluded people who were in long-term sickness absence at baseline. It is, therefore, likely that we both underestimated the level of sickness absence and the association between work stress and sickness absence. Another limitation is that our analysis relies on one of the established work stress models only. Other measures of work stress, however, are not available in the data (Karasek et al. 1998).

In sum, this study shows that work stress, as measured in terms of effort-reward imbalance, is linked to higher number of sickness absence, and that these effects of work stress on sickness absence tend to be higher among older workers. One implication is that policies aiming at increasing the workability of older workers should aim at creating age-friendly workplaces, and pay particular attention to older workers. A second, rather conceptual implication is that future studies on age-differences need to recognize that age represents a complex category that involves numerous, often varying experiences from previous life courses.

Acknowledgements This study was conducted in the frame of the german initiative "labour market participation at older ages" which is financed by the "fund for the future" of the Ministry of Innovation, Science and Research, North Rhine-Westphalia, Germany from 2016 to 2018. The authors are responsible for the content of the publication. Further support comes from the German Research Foundation (Deutsche Forschungsgemeinschaft) (project number: WA 3065/3-1).

\section{Compliance with ethical standards}

Conflict of interest The authors declare that they have no conflict of interest.

Ethical approval All procedures performed in studies involving human participants were in accordance with the ethical standards of the institutional and/or national research committee and with the 1964 Helsinki declaration and its later amendments or comparable ethical standards.

Open Access This article is distributed under the terms of the Creative Commons Attribution 4.0 International License (http://creativeco mmons.org/licenses/by/4.0/), which permits unrestricted use, distribution, and reproduction in any medium, provided you give appropriate credit to the original author(s) and the source, provide a link to the Creative Commons license, and indicate if changes were made.

\section{Appendix: Sensitivity analyses}

See Tables 8, 9 and 10 . 


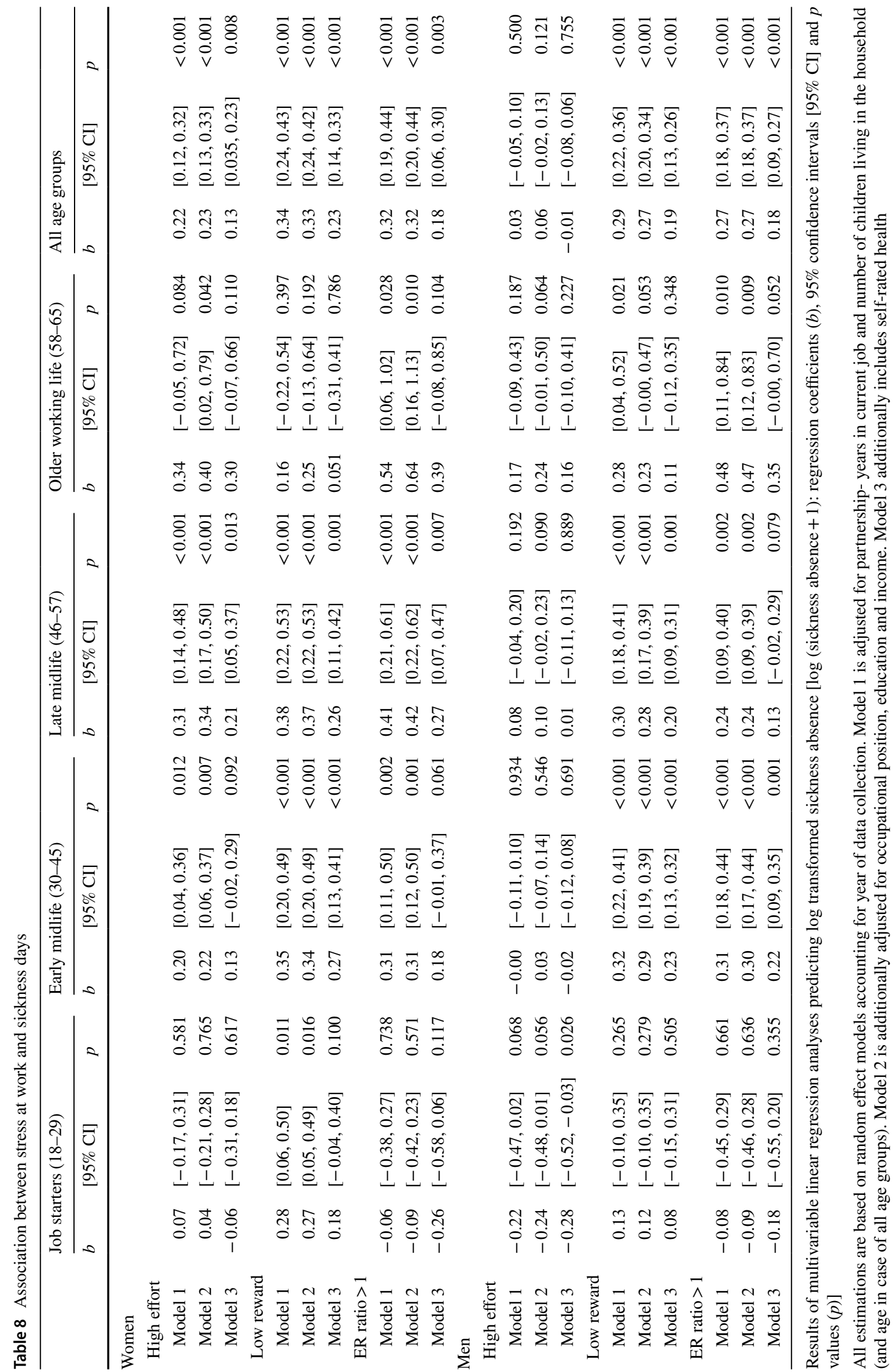









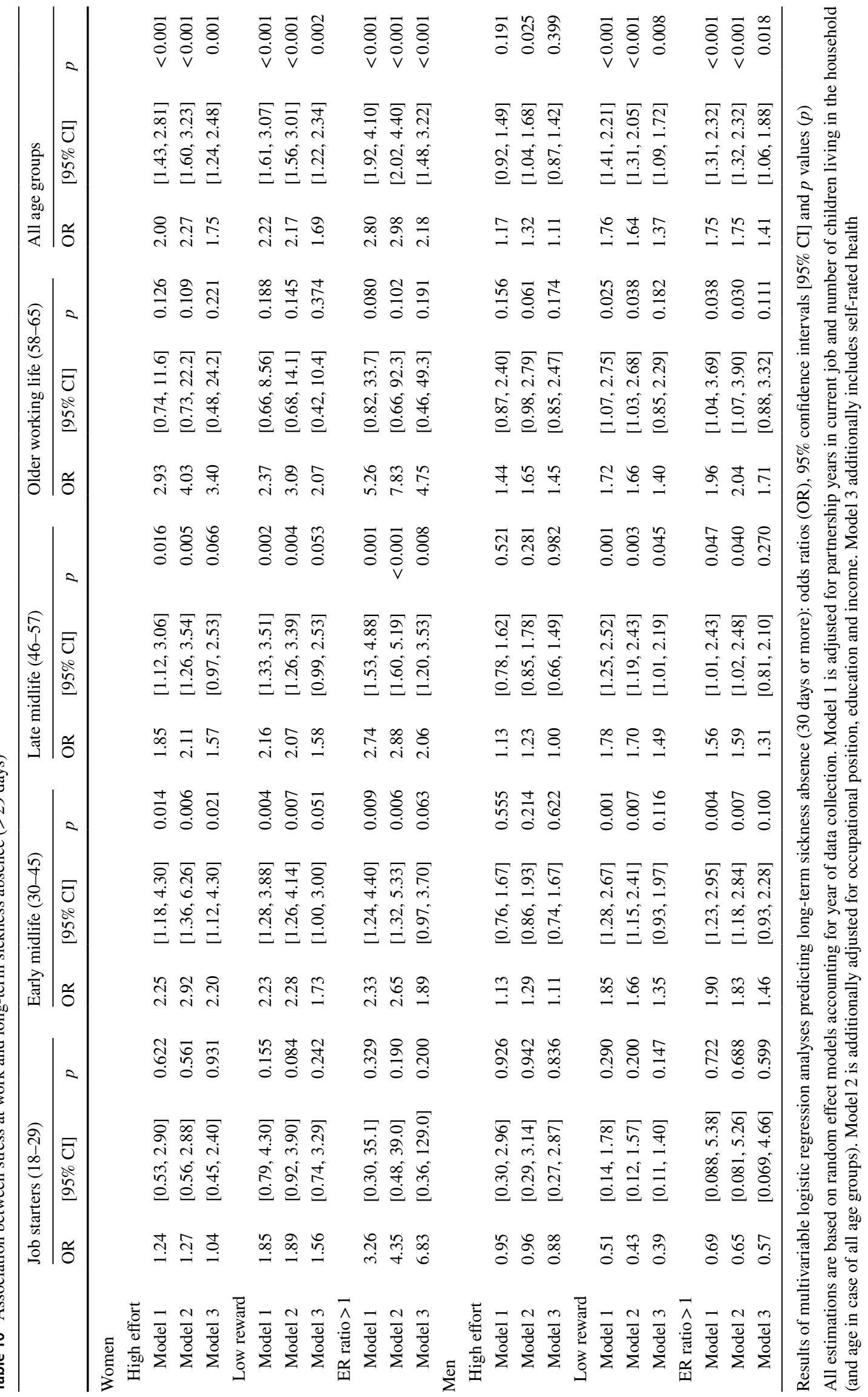




\section{References}

Ala-Mursula L, Vahtera J, Linna A, Pentti J, Kivimaki M (2005) Employee worktime control moderates the effects of job strain and effort-reward imbalance on sickness absence: the 10-town study. J Epidemiol Community Health 59(10):851-857. https:// doi.org/10.1136/jech.2004.030924

Andreß H-J, Golsch K, Schmidt AW (2013) Applied panel data analysis for economic and social surveys. Springer, New York

Beemsterboer W, Stewart R, Groothoff J, Nijhuis F (2009) A literature review on sick leave determinants (1984-2004). Int J Occup Med Environ Health 22(2):169-179. https://doi.org/10.2478/v1000 1-009-0013-8

Ben-Shlomo Y, Kuh D (2002) A life course approach to chronic disease epidemiology: conceptual models, empirical challenges and interdisciplinary perspectives. Int J Epidemiol 31(2):285-293. https:// doi.org/10.1093/ije/31.2.285

Brussig M, Ahlers E (2007) Krankheitsbedingte Fehlzeiten älterer Arbeitnehmer und Arbeitnehmerinnen im betrieblichen Kontext. Industrielle Beziehungen/Ger J Ind Relat 14(4):357-378

Burniaux J-M, Dang T-T, Fore D, Förster MF, Mira D'Ercole M, Oxley H (1998) Income distribution and poverty in selected OECD countries. OECD Econ Dep Work Pap 189:101. https:// doi.org/10.1787/730801800603

Burr H, Pohrt A, Rugulies R, Holtermann A, Hasselhorn HM (2017) Does age modify the association between physical work demands and deterioration of self-rated general health? Scand J Work Environ Health. https://doi.org/10.5271/sjweh.3625

Carstensen LL, Isaacowitz DM, Charles ST (1999) Taking time seriously: a theory of socioemotional selectivity. Am Psychol 54(3):165. https://doi.org/10.1037/0003-066X.54.3.165

Casini A, Godin I, Clays E, Kittel F (2013) Gender difference in sickness absence from work: a multiple mediation analysis of psychosocial factors. Eur J Public Health 23(4):635-642. https://doi. org/10.1093/eurpub/cks183

Cunradi CB, Greiner BA, Ragland DR, Fisher J (2005) Alcohol, stressrelated factors, and short-term absenteeism among urban transit operators. J Urban Health 82(1):43-57. https://doi.org/10.1093/ jurban/jti007

Derycke H, Vlerick P, van de Ven B, Rots I, Clays E (2013) The impact of effort-reward imbalance and learning motivation on teachers' sickness absence. Stress Health 29(1):14-21. https://doi. org/10.1002/smi.2416

Donders NC, Bos JT, van der Velden K, Van Der Gulden JW (2012) Age differences in the associations between sick leave and aspects of health, psychosocial workload and family life: a cross-sectional study. BMJ Open. https://doi.org/10.1136/bmjopen-2012-000960

du Prel J-B, March S, Schröder H, Peter R (2015) Berufliche Gratifikationskrisen und Arbeitsunfähigkeit in Deutschland. Bundesgesundheitsblatt Gesundheitsforschung Gesundheitsschutz 58(9):996-1004. https://doi.org/10.1007/s00103-015-2207-5

Elder GH,J, Johnson MK (2002) The Life Course and Aging: Challenges, Lessons, and New Directions. In: Setterston RA Jr (ed) Invitation to the life course: toward new understandings of later life, part 2. Baywood, Amityville, pp 49-81

Endler NS, Parker JD (1990) Multidimensional assessment of coping: a critical evaluation. J Pers Soc Psychol 58(5):844. https:// doi.org/10.1037/0022-3514.58.5.844

Erikson R, Goldthorpe JH (1992) The constant flux: a study of class mobility in industrial societies. Oxford University Press, USA

Eurofound (2010) Absence from work: European foundation for the improvement of living and working conditions. Eurofound, Dublin

Fahlén G, Goine H, Edlund C, Arrelöv B, Knutsson A, Peter R (2009) Effort-reward imbalance, "locked in" at work, and long-term sick leave. Int Arch Occup Environ Health 82(2):191-197. https://doi. org/10.1007/s00420-008-0321-5

Farquharson B, Allan J, Johnston D, Johnston M, Choudhary C, Jones M (2012) Stress amongst nurses working in a healthcare telephone-advice service: relationship with job satisfaction, intention to leave, sickness absence, and performance. J Adv Nurs 68(7):1624-1635. https://doi.org/10.111 1/j.1365-2648.2012.06006.x

Ferrie JE, Kivimaki M, Head J, Shipley MJ, Vahtera J, Marmot MG (2005) A comparison of self-reported sickness absence with absences recorded in employers' registers: evidence from the Whitehall II study. Occup Environ Med 62(2):74-79. https://doi. org/10.1136/oem.2004.013896

Giesselmann M, Windzio M (2012) Regressionsmodelle zur Analyse von Paneldaten. Lehrbuch. Springer, Wiesbaden

Harrison DA, Martocchio JJ (1998) Time for absenteeism: a 20-year review of origins, offshoots, and outcomes. J Manag 24(3):305350. https://doi.org/10.1177/014920639802400303

Head J, Kivimäki M, Siegrist J, Ferrie JE, Vahtera J, Shipley MJ, Marmot MG (2007) Effort-reward imbalance and relational injustice at work predict sickness absence: the Whitehall II study. J Psychosom Res 63(4):433-440. https://doi.org/10.1016/j.jpsychores .2007.06.021

Hobfoll SE (1989) Conservation of resources. A new attempt at conceptualizing stress. Am Psychol 44(3):513-524. https://doi. org/10.1037/0003-066X.44.3.513

Karasek R, Brisson C, Kawakami N, Houtman I, Bongers P, Amick B (1998) The job content questionnaire (JCQ): an instrument for internationally comparative assessments of psychosocial job characteristics. J Occup Health Psychol 3(4):322-355. https://doi. org/10.1037/1076-8998.3.4.322

Krantz G, Lundberg U (2006) Workload, work stress, and sickness absence in Swedish male and female white-collar employees. Scand J Public Health 34(3):238-246. https://doi. org/10.1080/14034940500327372

Kroh M, Kühne S, Siegers R, Deutsches Institut für Wirtschaftsforschung Berlin/Projektgruppe Das Sozio-Ökonomische Panel (2017) Documentation of sample sizes and panel attrition in the German socio-economic panel (SOEP) (1984 until 2015). SOEP survey papers, 408: Series C—data documentations (Datendokumentationen). DIW Berlin/SOEP, Berlin

Kuper H, Singh-Manoux A, Siegrist J, Marmot M (2002) When reciprocity fails: Effort-reward imbalance in relation to coronary heart disease and health functioning within the Whitehall II study. Occup Environ Med 59(11):777-784. https://doi.org/10.1136/ oem.59.11.777

Laaksonen M, Martikainen P, Rahkonen O, Lahelma E (2008) Explanations for gender differences in sickness absence: evidence from middle-aged municipal employees from Finland. Occup Environ Med 65(5):325-330. https://doi.org/10.1136/oem.2007.033910

Lazarus RS, DeLongis A (1983) Psychological stress and coping in aging. Am Psychol 38(3):245-254. https://doi. org/10.1037/0003-066X.38.3.245

Lidwall U (2016) Effort-reward imbalance, overcommitment and their associations with all-cause and mental disorder long-term sick leave-a case-control study of the Swedish working population. Int J Occup Med Environ Health 29(6):973. https://doi. org/10.13075/ijomeh.1896.00712

Matschinger H, Siegrist J, Siegrist K, Dittmann KH (1986) Type A as a coping career-toward a conceptual and methodological redefinition. In: Schmidt TH, Dembrovski TM, Blümchen T (eds) Biological and psychological factors in cardiovascular disease. Springer, Berlin, pp 104-126

McEwen BS (2012) Brain on stress: how the social environment gets under the skin. Proc Natl Acad Sci USA 109(Supplement 2):17180-17185. https://doi.org/10.1073/pnas.1121254109 
Messing K, Punnett L, Bond M, Alexanderson K, Pyle J, Zahm S, Wegman D, Stock SR, Grosbois S de (2003) Be the fairest of them all: challenges and recommendations for the treatment of gender in occupational health research. Am J Ind Med 43(6):618-629. https ://doi.org/10.1002/ajim.10225

Mitchell MN (2012) Interpreting and visualizing regression models using stata. Stata Press, College Station

Mortensen J, Dich N, Lange T, Alexanderson K, Goldberg M, Head J, Kivimaki M, Madsen IE, Rugulies R, Vahtera J, Zins M, Rod NH (2017) Job strain and informal caregiving as predictors of longterm sickness absence: a longitudinal multi-cohort study. Scand J Work Environ Health 43(1):5-14. https://doi.org/10.5271/sjweh .3587

Payne S, Doyal L (2010) Older women, work and health. Occup Med (Lond) 60(3):172-177. https://doi.org/10.1093/occmed/kqq030

Rugulies R, Aust B, Madsen IEH, Burr H, Siegrist J, Bültmann U (2012) Adverse psychosocial working conditions and risk of severe depressive symptoms. Do effects differ by occupational grade? Eur J Public Health 23(3):415-420. https://doi. org/10.1093/eurpub/cks071

Sampaio RF, Augusto VG (2012) Aging and work: a challenge for the rehabilitation schedule. Braz J Phys Ther 16(2):94-101. https:// doi.org/10.1590/S1413-35552012000200003

Scheibe S, Zacher H (2013) A lifespan perspective on emotion regulation, stress, and well-being in the workplace. In: Perrewé PL, Rosen CC, Halbesleben JRB (eds) The role of emotion and emotion regulation in job stress and well being. Emerald Group Publishing Limited, Bingley, pp 163-193

Schreuder JAH, Roelen CAM, Koopmans PC, Moen BE, Groothoff JW (2010) Effort-reward imbalance is associated with the frequency of sickness absence among female hospital nurses: a cross-sectional study. Int J Nurs Stud 47(5):569-576. https://doi. org/10.1016/j.ijnurstu.2009.10.002

Schupp J, Goebel J, Kroh M, Schröder C, Bartels C, Erhardt K, Fedorets A, Grabka M, Giesselmann M, Krause P, Kuehne S, Richter D, Siegers R, Schmelzer P, Schmitt C, Schnitzlein D, Wenzig K, German Institute for Economic Research (2016) Socio-Economic Panel (SOEP), data from 1984-2015. https:// doi.org/10.5684/soep.v32

Shultz KS (2010) Age differences in the demand-control model of work stress: an examination of data from 15 European countries. J Appl Gerontol 29(1):21. https://doi.org/10.1177/0733464809334286

Siegrist J (2016) A theoretical model in the context of economic globalization. In: Siegrist J, Wahrendorf M (eds) Work stress and health in a globalized economy: the model of effort-reward imbalance. Springer, Cham, pp 3-19
Siegrist J, Wahrendorf M (eds) (2016) Work stress and health in a globalized economy: the model of effort-reward imbalance. Springer, Cham

Siegrist K, Rödel A, Hessel A, Brähler E (2006) Psychosoziale Arbeitbelastungen, Arbeitsunfähigkeit und gesundheitsbezogenes Wohlbefinden: Eine empirische Studie aus der Perspektive der Geschlechterforschung (Psychosocial workload, sick leave, and health-related well being: an empirical study from the perspective of gender research). Gesundheitswesen 68(08/09):526-534. https ://doi.org/10.1055/s-2006-927073

Siegrist J, Wege N, Puhlhofer F, Wahrendorf M (2009) A short generic measure of work stress in the era of globalization: effort-reward imbalance. Int Arch Occup Environ Health 82(8):1005-1013. https://doi.org/10.1007/s00420-008-0384-3

Steel RP (2003) Methodological and operational issues in the construction of absence variables. Hum Resour Dev Rev. 13(2):243-251. https://doi.org/10.1016/S1053-4822(03)00015-9

Steers RM, Rhodes SR (1978) Major influences on employee attendance: a process model. J Appl Psychol 63(4):391. https://doi. org/10.1037/0021-9010.63.4.391

Sterud T (2014) Work-related gender differences in physician-certified sick leave: a prospective study of the general working population in Norway. Scand J Work Environ Health 40(4):361-369. https:// doi.org/10.5271/sjweh.3427

Stoto MA, Emerson JD (1983) Power transformations for data analysis. Sociol Methodol 14:126-168. https://doi.org/10.2307/270905

Taimela S, Laara E, Malmivaara A, Tiekso J, Sintonen H, Justen S, Aro T (2007) Self-reported health problems and sickness absence in different age groups predominantly engaged in physical work. Occup Environ Med 64(11):739-746. https://doi.org/10.1136/ oem.2006.027789

Voss M, Stark S, Alfredsson L, Vingard E, Josephson M (2008) Comparisons of self-reported and register data on sickness absence among public employees in Sweden. Occup Environ Med 65(1):61-67. https://doi.org/10.1136/oem.2006.031427

Wagner GG, Frick JR, Schupp J (2007) The German socio-economic panel study (SOEP)—evolution, scope and enhancements. SSRN J. https://doi.org/10.2139/ssrn.1028709

Wahrendorf M, Chandola T (2016) A life course perspective on work stress and health. In: Siegrist J, Wahrendorf M (eds) Work stress and health in a globalized economy: the model of effort-reward imbalance. Springer, Cham, pp 43-66

Willis SL, Martin M (2005) Middle adulthood: a lifespan perspective. Sage, Thousand Oaks 